\title{
Combustion synthesis process for the rapid preparation of high-purity SrO powders
}

\author{
Francisco GranAdos-CORREA*, JUAN BONIFACIO-MARTÍNEZ \\ Instituto Nacional de Investigaciones Nucleares, Departamento de Química, A.P. 18-1027. Col. Escandón, Delegación Miguel \\ Hidalgo. C.P. 11801 México, D.F., México
}

\begin{abstract}
A rapid, safe and simple technique for the production of high purity strontium oxide powders via a chemical combustion process is reported. The combustion reactions were performed to optimize the fuel to oxidizer ratios in the reaction mixtures required to obtain pure $\mathrm{SrO}$ powders by varying the molar ratio of chemical precursors and the temperature. The synthesized powders were characterized by X-ray diffraction, scanning electron microscopy, energy dispersive X-ray spectrometry, infrared spectroscopy, differential scanning calorimetry, thermogravimetric analysis, and $\mathrm{N}_{2}$-physisorption measurements. The results indicate that crystalline $\mathrm{SrO}$ was obtained using a 1:1 strontium nitrate: urea molar ratio at $1000{ }^{\circ} \mathrm{C}$ after 5 minutes. In addition, high-purity, homogeneous and crystalline $\mathrm{SrO}$ powders were easily produced in a short time via a chemical combustion process.
\end{abstract}

Keywords: strontium oxide; chemical combustion; XRD; IR spectral analysis; thermal analysis

(C) Wroclaw University of Technology.

\section{Introduction}

In the past, the most extensive use of strontium oxide powder $(\mathrm{SrO})$ was in the cathode ray tubes industry where it was employed in the form of an aluminum alloy to help protect humans from X-ray emissions in traditional color televisions. However, this long-lasting technology has now been replaced by the widespread use of flat displays (i.e. either liquid crystal or plasma displays). Recently, $\mathrm{SrO}$ powders have been essential in novel technological applications in the chemical and electronic industries, including the production of ferrite ceramic magnets and zinc refining [1]. In addition, because $\mathrm{SrO}$ is electronically conductive, it has been used in fuel cells and oxygen generation systems as a cathode material in the solid oxide form. Due to its optical properties, strontium oxide has been employed to improve the quality of special glasses. In addition, diverse strontium salts are currently consumed as pyrotechnic materials or paint additives [2], or employed in fuel production catalysis [3]. Due to some unusual physical and chemical properties, strontium oxide has the potential for use in medical appliances, such as tissue or body

*E-mail: francisco.granados@inin.gob.mx member replacements, restorative implant cement or filling compounds [4].

Although the consumption demands fluctuate from year to year, the overall consumption of strontium compounds and metals appears to be increasing [4]. Therefore, diverse technologies for the synthesis of advanced ceramic materials, such as strontium oxide, have been investigated to discover new cost effective and efficient methods of production. It is important to note that nanocrystalline strontium oxide has been previously prepared using aerogel and conventional methods that have yielded small amounts of product. In recent years, combustion synthesis has become a promising technique because it is a fast and straightforward process that produces homogeneous, very fine, and crystalline multicomponent oxide ceramic powders $[5,6]$.

The chemical combustion synthesis is based on the principle of explosive decomposition of nitrate reagents and fuel mixtures using the instantaneous heat generated by the chemical reaction between the fuel and nitrates to convert the metal ions into the target ceramic material [7]. The classical combustion synthesis consists in placing an aqueous solution that contains salts of the metal of interest (the nitrates of the metal due to their good 
water solubility are typically preferred) in contact with an appropriate organic fuel, such as urea, at temperatures of 400 to $1100{ }^{\circ} \mathrm{C}$. When the mixture begins to warm up, it generates instantaneous heat that initiates a very fast and abrupt exothermal reaction that yields a metallic oxide in the form of a fine powder, which is crystalline, amorphous, or semicrystalline and ready for use as advanced ceramics with interesting magnetic, dielectric, electrical, mechanical, luminescent, catalytic, and optical properties [8-12]. The combustion process is characterized by high temperatures, fast heating and short reaction times. These characteristics make the combustion method an attractive technique for the manufacture of technologically useful materials at a lower cost compared to conventional ceramic processes where some require long heating times and equipment. Therefore, the metallic oxides obtained through chemical combustion provide an interesting alternative compared to other complex synthesis processes because chemical combustion offers attractive advantages, such as simplicity as it requires little specialized equipment and enables rapid preparation of a product with optimal structural and functional properties. Typically, products of combustion synthesis are highly reactive and pure and contain minimum level of impurities. Currently, several researchers have employed the combustion method to synthesize a variety of oxide ceramic powders with good success $[13,14]$. In previous studies, we have reported a successful synthesis of inorganic materials via chemical combustion along with their complete characterizations and demonstrated their potential for application in environment remediation [15-18]. However, synthesis of SrO via chemical combustion has not been reported yet. Therefore, the aim of this study is to report the synthesis of pure $\mathrm{SrO}$ powder using the chemical combustion method. In addition, the particle structure and surface properties are discussed.

\section{Experimental}

\subsection{Materials and methods}

Strontium nitrate (Baker $98.5 \%$ purity) and the urea reagent (Sigma-Aldrich $99.9 \%$ purity) were used without further purification. Distilled water was used to prepare the solutions, and the urea was used as a fuel for the combustion reaction. The chemical combustion of strontium nitrate and urea as precursors was employed for the synthesis of SrO.

\subsection{SrO synthesis by chemical com- bustion}

To establish the best experimental conditions of $\mathrm{SrO}$ formation, suitable reaction parameters, such as the molar ratio of chemical precursors (i.e. strontium nitrate and urea $(1: 1$ to $1: 2.5))$ and the reaction temperature (i.e. 800,900 , and $1000^{\circ} \mathrm{C}$ ), were tested to obtain a pure $\mathrm{SrO}$ powder. The appropriate chemical precursors were transferred to a $50 \mathrm{~mL}$ crucible, and the mixture was suspended in $1 \mathrm{~mL}$ of distilled water until a homogeneous solutions was obtained. Then, the mixture was heated until most of the water evaporated with the aid of an electric grill, resulting in a humid integrated solid. Next, this solid was heated at the reaction temperatures mentioned above for $5 \mathrm{~min}$ for the constant reaction time synthesis.

\subsection{Characterization}

The synthesized powders were characterized via various techniques. X-ray diffraction (XRD) patterns were performed on a Siemens D5000 X-ray diffractometer with $\mathrm{CuK} \alpha$ radiation. Joint Committee on Powder Diffraction Standard (JCPDS) file software was employed to determine the composition phases of the samples. Thermal analysis tests were performed using differential scanning calorimeter-thermogravimetric analysis (DSC-TGA) on a SDT Q600 calorimeter TA Instrument-Waters equipment. The samples were heated at a rate of $10^{\circ} \mathrm{C} \cdot \mathrm{min}^{-1}$ under air flow of $100 \mathrm{~mL} \cdot \mathrm{min}^{-1}$ from room temperature to $1000^{\circ} \mathrm{C}$. Infrared (IR) spectroscopy analysis was performed using an IR Nicolet Magna 550 spectrophotometer using a $\mathrm{KBr}$ disc. The microstructure and chemical composition of the powders obtained by combustion were examined using a scanning electron microscopy (SEM) with energy dispersive X-ray spectroscopy (EDS) analysis on a JEOL-JMS 5900. 
The Brunauer-Emmett-Teller (BET) specific surface area, mean pore diameter, total pore volume, and the adsorption-desorption isotherm of the optimum synthesized material were determined by $\mathrm{N}_{2}$-physisorption measurements with a BelsorpMax Japan INC apparatus, and the samples were degassed at $300{ }^{\circ} \mathrm{C}$ for $2 \mathrm{~h}$ prior to performing the measurements.

\section{Results and discussion}

\subsection{Synthesis of $\mathrm{SrO}$}

The effect of molar ratio of the chemical precursors and reaction temperature on the combustion synthesis of $\mathrm{SrO}$ was investigated. First, the experiments were conducted using different molar ratios (i.e. 1:1, 1:1.5, 1:2.0, and 1:2.5) of the chemical precursors (i.e. strontium nitrate and urea) and the combustion method described above at $800{ }^{\circ} \mathrm{C}$, $900{ }^{\circ} \mathrm{C}$ and $1000{ }^{\circ} \mathrm{C}$, in a muffle furnace under atmospheric pressure with a constant reaction time of $5 \mathrm{~min}$.

The best conditions for $\mathrm{SrO}$ synthesis occurred at a molar ratio of strontium nitrate to urea of 1:1 at $1000{ }^{\circ} \mathrm{C}$ for $5 \mathrm{~min}$. This reaction involves the exothermic reaction of an organic fuel (i.e., urea) in the furnace chamber, which produces metal oxides via reduction of the metal nitrate [19]. Therefore, metal oxide products, gas emission of $\mathrm{CO}_{2}$, $\mathrm{H}_{2} \mathrm{O}$, and nitrogen oxides $\left(\mathrm{NO}_{2}\right)$ as well as other products can be formed directly from the reaction between metal nitrate and urea without using external oxygen. The resulting final products of rapid combustion are very fine white powders, and the balanced combustion reaction for the formation of the $\mathrm{SrO}$ phase in this study can be written as:

$$
\begin{aligned}
& 2 \mathrm{Sr}\left(\mathrm{NO}_{3}\right)_{2}+3 \mathrm{NH}_{2}-\mathrm{CO}-\mathrm{NH}_{2} \rightarrow 2 \mathrm{SrO}+ \\
& +2 \mathrm{NO}_{2}+3 \mathrm{CO}_{2}+3 \mathrm{~N}_{2}+2 \mathrm{NH}_{3}+3 \mathrm{H}_{2} \mathrm{O}
\end{aligned}
$$

The presence of urea in the combustion reaction produced $\mathrm{SrO}$ powders in a short reaction time (i.e. 5 minutes).

\subsection{Characterization}

\subsubsection{X-ray diffraction study}

Fig. 1 shows the X-ray diffraction patterns of the $\mathrm{SrO}$ products synthesized by chemical combustion at a strontium nitrate to urea molar ratio of $1: 1$ heated at 800,900 and $1000{ }^{\circ} \mathrm{C}$ for 5 minutes. When the sample was calcined at $800{ }^{\circ} \mathrm{C}$ (sample $\mathrm{SrO}-\mathrm{A}$ ), the XRD pattern indicated the presence of three well-defined crystalline phases (i.e. $\mathrm{SrO}, \mathrm{SrCO}_{3}$ and $\mathrm{Sr}(\mathrm{OH})_{2}$ ) with $\mathrm{SrO}$ as the dominant phase (Fig. 1a). However, when the same sample was heated at $900{ }^{\circ} \mathrm{C}$ (sample $\mathrm{SrO}-\mathrm{B}$ ), the results in Fig. 1b, indicate that the sample primarily consisted of $\mathrm{SrO}$ with minor intensities of $\mathrm{SrCO}_{3}$ and $\mathrm{Sr}(\mathrm{OH})_{2}$ impurities formed during the combustion reaction. For the sample heated at $1000{ }^{\circ} \mathrm{C}$ $(\mathrm{SrO}-\mathrm{C})$, the results in Fig. 1c indicate the presence of only one crystalline phase corresponding to the crystalline SrO phase in the final product, according to the JCPDS file No. 75-0263. The XRD patterns (results no shown) of the samples obtained at 800,900 and $1000{ }^{\circ} \mathrm{C}$ with different molar ratios of the chemical precursors (i.e. 1:1.5 to 1:2.5) were analyzed. In these cases, a reaction temperature of $800{ }^{\circ} \mathrm{C}$ also resulted in the presence of three crystalline phases (i.e. $\mathrm{SrO}, \mathrm{SrCO}_{3}$ and $\mathrm{Sr}(\mathrm{OH})_{2}$ ). However, a decrease in the relative peak intensity of $\mathrm{SrO}$ was observed, and the relative intensities of the peaks corresponding to $\mathrm{SrCO}_{3}$ and $\mathrm{Sr}(\mathrm{OH})_{2}$ phases increased when the samples with molar ratios of $1: 1.5$ to $1: 2.5$ were heated at $900{ }^{\circ} \mathrm{C}$. These results suggest that the heat produced by the instantaneous combustion of urea must be the principal heat source for $\mathrm{SrO}$ production and that an increased amount of urea $(>1.5)$ favored the production of the strontium carbonate and strontium hydroxide phases. Therefore, the differences observed in the synthesis of $\mathrm{SrO}$ were due to the stoichiometric amount of fuel (urea), and the urea combustion was shown to be an important factor initiating SrO synthesis, which has been observed by Cruz et al. [20] for the synthesis of $\mathrm{Li}_{2} \mathrm{MO}_{3}(\mathrm{M}=\mathrm{Ti}$ or $\mathrm{Zr})$ using a combustion method where a stoichiometric relationship of the chemical precursors was determined to be 1:1. Based on these results, well-crystallized $\mathrm{SrO}$ powder can be easily obtained under the 
experimental conditions described above (i.e. strontium nitrate to urea molar ratio of $1: 1$ at $1000{ }^{\circ} \mathrm{C}$ for $\left.5 \mathrm{~min}\right)$.

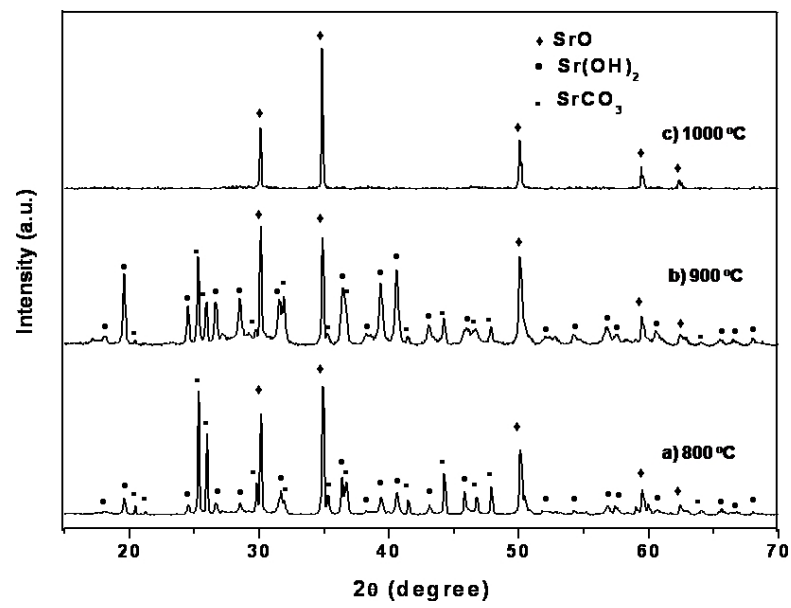

Fig. 1. XRD patterns for the $\mathrm{SrO}$ powders prepared using combustion method at a molar ratio of strontium nitrate to urea $1: 1$, at different temperatures, for $5 \mathrm{~min}$.

\subsubsection{Thermal analysis study}

The thermal studies of the sample were carried out at a heating rate of $10{ }^{\circ} \mathrm{C} / \mathrm{min}$ up to $1000{ }^{\circ} \mathrm{C}$ for 5 minutes, and the TGA/DSC curves are shown in Fig. 2. It can be observed that the thermal decomposition process proceeds in four stages. The first step, corresponds to the dehydration of the hydroxyl water of $\mathrm{SrOOH}$, which is transformed to $\mathrm{SrO}$ resulting in a weight loss of $2.19 \%$. The second mass loss corresponds to the release of cyanic acid and other volatile product, such as $\mathrm{NO}_{2}$, with a weight loss of $2.48 \%$. The third step corresponds to the release of nitrous fumes and $\mathrm{CO}_{2}$ with a weight loss of $47.58 \%$. The final step is due to the crystallization of $\mathrm{SrO}$ with a weight loss of $1.63 \%$. The net weight loss of the compound was determined to be $53.88 \%$. In the DSC curves there are endothermic peaks below $291.9^{\circ} \mathrm{C}$ caused by the vaporization of physically bound absorbed water and dehydration of the powders. In addition, an exothermic peak, which corresponds to decomposition can be observed at $495{ }^{\circ} \mathrm{C}$. Such an exothermic reaction is a result of a thermally induced redox reaction where urea acts as a reductant and nitrate as an oxidant. Next, two sharp endothermic peaks are observed at approximately 617.5 and $668.4{ }^{\circ} \mathrm{C}$ due to the phase formation of SrO, as shown in Fig. 2. This behavior indicates that the formation reaction is very fast and explosive above $600{ }^{\circ} \mathrm{C}$, and the end product is stable from $740{ }^{\circ} \mathrm{C}$ to $1015{ }^{\circ} \mathrm{C}$. Therefore, the succeeding horizontal line is due to $\mathrm{SrO}$. TGA-DSC studies confirm the phase formation of $\mathrm{SrO}$ during the heating process, which is consistent with the behavior reported by Cambpell et al. [21]. Cambpell et al. determined that the formation of $\mathrm{SrO}$ by the calcination of strontium nitrate, started at $600{ }^{\circ} \mathrm{C}$ and was completed at $745{ }^{\circ} \mathrm{C}$. In addition, the reported end product was $\mathrm{SrO}$, which was stable up to $1000{ }^{\circ} \mathrm{C}$. In our case, the end product was confirmed by XRD analysis.

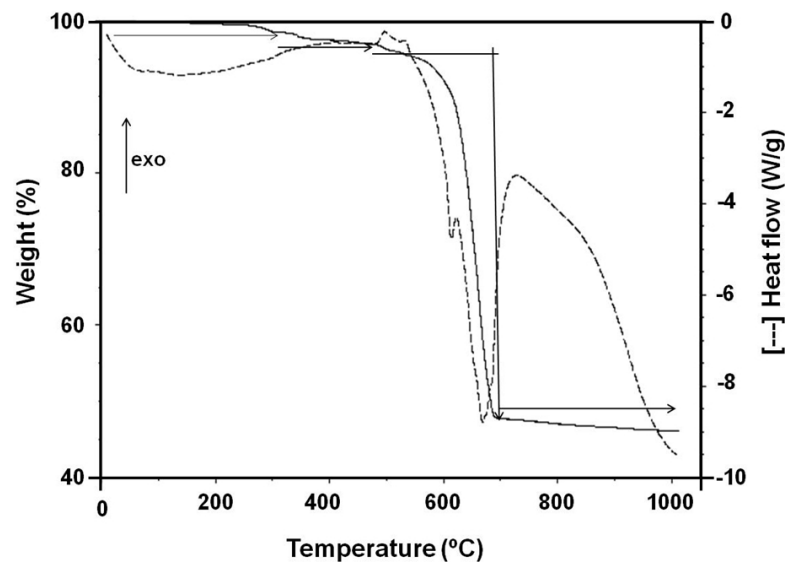

Fig. 2. DSC-TGA curves of SrO prepared by the combustion method at $1000{ }^{\circ} \mathrm{C}$ for $5 \mathrm{~min}$.

\subsubsection{Infrared spectral study}

The infrared spectrum of the sample obtained at urea to strontium nitrate molar ratio of $1: 1$ at $1000{ }^{\circ} \mathrm{C}$ (sample $\mathrm{SrO}-\mathrm{C}$ ) is shown in Fig. 3. The IR bands of $\mathrm{SrO}$ are shown over the wavelength range of 4000 to $400 \mathrm{~cm}^{-1}$ and the broad band at $3497 \mathrm{~cm}^{-1}$ corresponds to the $\mathrm{OH}^{-1}$ stretching vibration due to hydroxyl functional groups as well as hydrogen bonding. The peaks at $2357 \mathrm{~cm}^{-1}$ and $2341 \mathrm{~cm}^{-1}$ indicate the presence of $\mathrm{K}-\mathrm{Br}$ stretching. The band at $1709 \mathrm{~cm}^{-1}$ caused by the presence of conjugated $\mathrm{C}-\mathrm{O}$, which is most likely related to the presence of $\mathrm{CO}_{2}$ due to the IR study performed under uncontrolled atmospheric conditions. 
The band at $1444 \mathrm{~cm}^{-1}$ may be due to bending vibrations from $\mathrm{O}-\mathrm{H}$ groups. The band at $1036 \mathrm{~cm}^{-1}$ can be assigned to $\mathrm{Sr}-\mathrm{O}-\mathrm{Sr}$ stretching vibrations. Therefore, the IR spectra confirm the formation of $\mathrm{SrO}$ with hydroxyl groups due to the presence of surface water and do not exhibit bands corresponding to organic residues. Similar observations have been reported in the literature for the synthesis of $\mathrm{Ni}$ powder by microwave-assisted combustion using urea as a fuel [22].

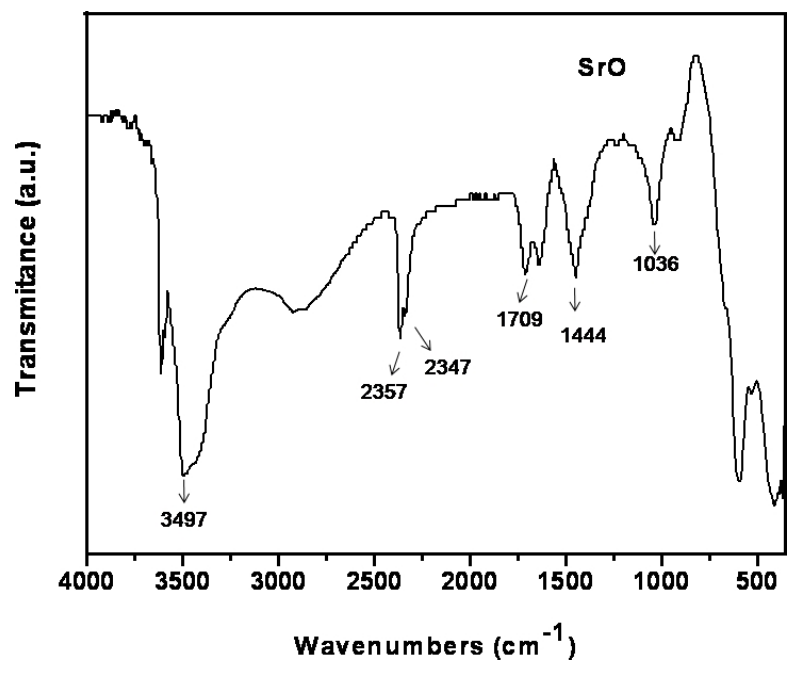

Fig. 3. IR spectrum of $\mathrm{SrO}$ synthesized by chemical combustion at $1000{ }^{\circ} \mathrm{C}$ for $5 \mathrm{~min}$.

\subsubsection{SEM-EDS study}

The morphology of the as-synthesized material (sample $\mathrm{SrO}-\mathrm{C}$ ) is shown in Fig. 4. As shown in Fig. 4, the combustion reaction product (i.e. $\mathrm{SrO}$ ) is observed as square lamina-like aggregates consisting of particles with smooth surfaces. In addition, the SEM micrograph of the $\mathrm{SrO}-\mathrm{C}$ sample shows various $\mathrm{SrO}$ particles that are 1 to $30 \mu \mathrm{m}$ in size after $5 \mathrm{~min}$ of chemical combustion at $1000{ }^{\circ} \mathrm{C}$. The EDS analysis in Fig. 4 confirms that the $\mathrm{SrO}$ particles consist only of strontium and oxygen elements.

\subsection{5. $\quad \mathbf{N}_{2}$-physisorption measurements}

$\mathrm{N}_{2}$-physisorption measurements indicate that the BET specific surface area value for $\mathrm{SrO}$ (sample $\mathrm{SrO}-\mathrm{C}$ ) is $4.45 \mathrm{~m}^{2} / \mathrm{g}$, the total pore volume is $8.10 \times 10^{-3} \mathrm{~cm}^{3} / \mathrm{g}$, and the mean pore

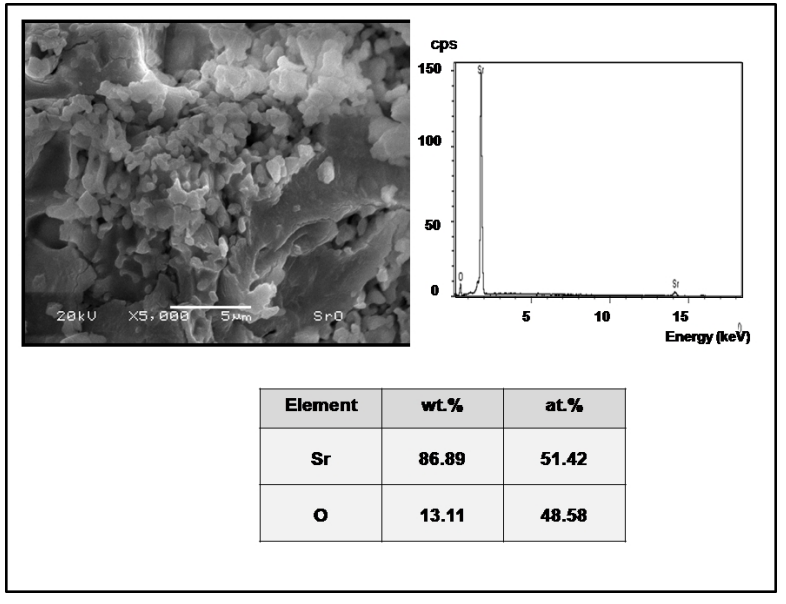

Fig. 4. SEM image and EDS analysis of a SrO sample prepared by chemical combustion at $1000^{\circ} \mathrm{C}$ for 5 min.

diameter is $29.41 \mathrm{~nm}$. Fig. 5 shows the $\mathrm{N}_{2}$ adsorption-desorption isotherm obtained for the synthesized compound (i.e. sample $\mathrm{SrO}-\mathrm{C}$ ). According to the International Union of Pure and Applied Chemistry (IUPAC), SrO exhibits an isotherm type II, which is typically associated with nonporous materials, as observed in our SEM study. The adsorption of gases and vapors give rise to I - IV types of adsorption isotherms with different characteristics, which are primarily dependent on the structure of the solids. Type II isotherms, which are observed in the physical adsorption of gases by non-porous solids, are multilayered and often referred to as sigmoid isotherms [23].

\section{Conclusions}

Strontium oxide was synthesized using a combustion method, and the results from several analytical tests indicate that the prepared material consists of a highly crystalline phase. The procedure involved using a molar ratio of strontium nitrate to urea $1: 1$ and heating at $1000{ }^{\circ} \mathrm{C}$ for $5 \mathrm{~min}$. This procedure represents a novel method for producing a useful oxide ceramic material. The use of a combustion method to obtain this ceramic material resulted in the production of an advanced material. In addition, no more than $5 \mathrm{~min}$ were required for the synthesis reaction to obtain the final pure $\mathrm{SrO}$ powders. 


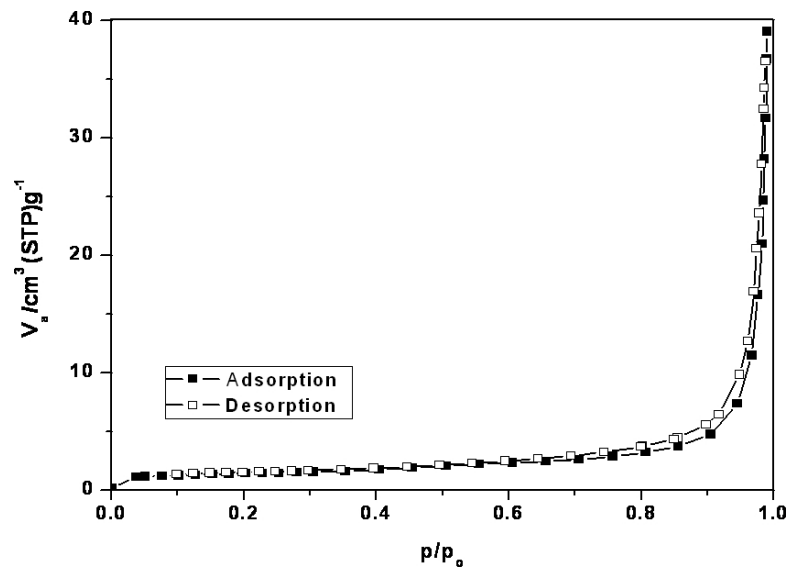

Fig. 5. Nitrogen adsorption-desorption isotherm of a SrO sample synthesized using chemical combustion at $1000{ }^{\circ} \mathrm{C}$ for $5 \mathrm{~min}$.

\section{Acknowledgements}

The authors wish to thank ININ, México, for financial support through Department Activity No. DIO2B. The authors also wish to thanks Jorge Cid del Prado and Isidoro MartínezMera for providing the XRD, SEM, and EDS facilities.

\section{References}

[1] Yu J., Guo H., Cheng B., J. Solid State Chem., 179 (2006), 800.

[2] Li S., Zhang H., Xu J., Yang D., Mater. Lett., 59 (2005),420.

[3] Yoosuk B., Krasae P., Puttasawat B., Udomsap P., Viriya-EMPikUl N., FAUngnawaKiJ K., Chem. Eng. J., 162 (2010), 58.

[4] Joyce A.O., Strontium, Minerals Yearbook. Volume 1. Metals and Minerals, US, Bureau of Mines, 1992, 11323.

[5] Ozuna O., Hirata G.A., Kittrick M.C., J. Phys.Condens. Mat., 16 (2004), 2585.

[6] Chandrappa K.G., Venkatesha T.V., Nayana K.O., PunithKumar M.K., Mater. Corros., 63 (2012), 445.
[7] Kingsley J.J., Pederson L.R., Mater. Lett., 18 (1993), 89.

[8] Chandran R.G., Patil K.C., Mater. Lett., 10 (1990), 291.

[9] Manoharan S.S., Patil K.C., J. Am. Ceram. Soc., 75 (1992), 1012.

[10] Li F., Hu, J. L., Zhang L.D., Chen G., J. Nucl. Mater, 300 (2002), 82.

[11] Patil K.C., Aruna S.T., Mimami T., Curr. Opin. Solid St. M., 6 (6) (2002), 507.

[12] Biamino S., Badini C., J. Eur. Ceram. Soc., 24 (2004), 3021.

[13] Chick L.A., Pederson L.R., Maupin G.D., Bates J.L., Thomas L.E., Exarhos G.H., Mater. Lett., 10 (1990), 6.

[14] Sharma S.K., Pitale S.S., Malik P.M., Dubey R.N., QuReshi M.S., OJHA S., Physica B, 405 (2010), 866.

[15] Granados-Correa F., Bonifacio-Martínez J., Lara V.H., Bosch P., Bulbulian S., Appl. Surf. Sci., 254 (2008), 4688.

[16] Alvarado-Ibarra Y., Granados-Correa F., Lara V.H., Bosch P., Bulbulian S., Colloid. Surface A, 345 (2009), 135.

[17] Granados-Correa F., Jiménez-Reyes M., Sep. Sci. Technol., 46 (2011), 2360.

[18] Medine G.M., Klabunde K.J., ZaikovskiI V., J. Nanopart. Res., 4 (2002),357.

[19] Mathews T., Subasri R., Sreedharan O.M., Solid State Ionics, 148 (2002), 135.

[20] Cruz D., Pfeiffer H., Bulbulian S., Solid State Sci., 8 (2006), 470.

[21] Campbell P.F., Ortner M.H., Anderson C., Anal. Chem., 33 (1961), 58.

[22] Sahu R.K., Ray A.K., Das S.K., Kailath A.J., PATHAK L.C., J. Mater. Res., 21 (2006), 1664.

[23] Lowell S., Introduction to Powder Surface Area, Interscience Publishers, Toronto, Canada, 1979.

Received 2014-06-20 Accepted 2014-09-03 